\title{
Complex factors and educational tools for social change and empowerment for severely marginalized Nepalese women working in hospitality and tourism
}

\author{
Jay R. Deagon ${ }^{1 *}(\mathbb{0}$, Miriam Ham² and Wendy Hillman³
}

${ }^{*}$ Correspondence:
j.deagon@cqu.edu.au
${ }^{1}$ School of Education
and the Arts, CQUniversity,
Rockhampton, Australia
Full list of author information
is available at the end of the
article

*Correspondence: j.deagon@cqu.edu.au School of Education d the Arts, CQUniversity, article

\begin{abstract}
Educated and skilled women are active change agents. This paper focuses on informal hospitality education as a tool for social change and empowerment for severely marginalized Nepalese women. Studied over 18 months, a small group of women cooking for a boutique local and international tourist market in Kathmandu participated in cookery skills training. The Australian educator/researchers focused on the educational experience to uptake and retention of cookery skills and technical language. As a result of the educational intervention, changes in personal attributes and perceptions of inherent sociocultural gender roles/caste emerged. Participation in the cookery skills training program contributed partially as a catalyst that improved confidence, communication skills and exposed to the women pathways toward self-sustainability, emancipation and empowerment within an often-hostile working environment for women from severely disadvantaged backgrounds in Nepal.
\end{abstract}

Keywords: Confidence, Cookery, Education, Empowerment, Hospitality, Marginalized, Women, Nepal

\section{Introduction}

An evaluation of educational reform in Nepal has advocated for an increased focus on the 'soft skills' of Nepali life and culture into formalized education (GFA Consulting Group 2016). Access to quality Vocational Education and Training (VET) courses is limited in Nepal; however, acutely felt by women in the area of qualifications for employment in hospitality and tourism. The study reported in this paper examined how the researchers used an internationally developed hospitality curriculum to guide training designed to increase the skills of marginalized women in their entrepreneurial cookery business venture operating under a joint Australia/Nepal Social Enterprise in Kathmandu. The established social enterprise venture provides half-day Nepali cookery lessons with tourists from local and international backgrounds. The organization uses a sustainable and innovative business model to provide income and training for marginalized women to 
operate the cookery school but with a long-term view of providing them with the skills and experience to gain employment in Nepal's hospitality industry.

In its 4 years of operation, the cookery school has proven very successful. However, the rapid success has been overwhelming for the underprepared group of women. The women needed to be equipped with skills and confidence to meet the demands of the increasing level of clientele, specifically to combat the women's perception that they were not adequately skilled to conduct the cookery school because they did not have any formal qualifications. When interacting with tourists, this perception appeared to impact their confidence levels and hampered their ability to operate effectively, both in the cookery school and in training other women. Our research investigated this perception and sought to co-design training solutions that would provide skills and knowledges to empower the women.

\section{Challenges for women in Nepal}

From the perspective of three female socially and economically privileged Australian researchers, Nepal's caste and patriarchal system seemed an extraordinarily daunting environment for women, which directly hampers their autonomy and constantly dispossess them of their self-confidence (Atteraya et al. 2016; Hillman and Radel 2021). In Nepal, the 103 varied caste/ethnic groupings who communicate in 92 languages represent a broad disparity of adversity levels and contrasting social categories (Gurung 1995; Hatlebakk 2008). Women endure the caste system, unyielding gender discrimination and male-controlled stratification (McMillan et al. 2011). These constraints are evidenced in the literacy indicators where the literacy rate of males is significantly higher (76.4\%) than females (53.1\%) (Central Intellegence Agency 2019). The Nepal Demographic and Health Survey 2016 reported that upwards of 1 in 10 (12\%) females aged 15-49 years old had been the victims of sexual violence. Alarmingly, females working in paid employment are more likely to have been the targets of sexual violence (18\%), more so than females who are working but do not receive an income (11\%), or females who are working at all (also 11\%) (Ministry of Health and Population 2012). Women with disabilities trying to gain employment in Nepal face a wide range of systematic, social-cultural and individual barriers that limit their opportunities (Gupta et al. 2018).

\section{Hospitality, tourism and cultural exchange: a vehicle for empowerment and self-sustainability}

There is a global trend toward economic advancement through increased reliance on entrepreneurship (Coyne and Leeson 2004; Galloway et al. 2005; Hisrich and Ayse Öztürk 1999). Small entrepreneurial hospitality and tourism ventures are emerging in Nepal to cater for increased tourist traffic (Hillman 2019; McMillan et al. 2011). However, women's access to entrepreneurial ventures has been impeded comprehensively (Verheul and Thurik 2001). International literature indicates that growth organizations recommend incorporating females into all factors of tourism and broader pecuniary efforts, subsequently providing females with the option to nurture administration proficiency and attain wide-ranging identification within their communities (Scheyvens 2000). Foreign development groups actively champion Nepali women's self-assurance to occupy the tourism space by delivering training 
and coaching (Gurung 1995). These foreign development groups make plain their conviction that ventures should integrate women into all components of their undertakings. Subsequently, presenting that women can cultivate leadership proficiency and realize a more expansive level of respect within their communities (Hillman 2019; Scheyvens 2000). The advance in women's standing presents an ideal situation for Nepal to generate gender equivalence in terms of occupation to address the hurdles and barriers discouraging many womenfolk in urban, rural and remote Nepal from becoming reliable and distinct wage earners within a tourism occupation (Hillman and Radel 2021; Hillman 2019; McMillan et al. 2011; Wilkinson and Pratiwi 1995).

Although limited in number, there are examples of successful entrepreneurship of Nepalese women in the hospitality and tourism sector in the literature. A small-scale study in the Annapurna region of Nepal investigated the notion of women's empowerment through their ownership and operation of tea houses by Nepalese women (McMillan et al. 2011). McMillan et al. (2011) asserted that women were empowered economically, socially and psychologically through their active participation in commercial hospitality activities. They state that "somewhat ironically... the traditional roles which had once been the cause of their marginalization [soft skills and "female" skills of cookery and household caretaking], have now become the root of their empowerment" (McMillan et al. 2011). In their study, the participants experienced some resistance from village men because they broke from traditional gender roles. Consequently, McMillan et al. (2011) suggested and Hillman and Radel (2021) affirm, that in the current patriarchally dominant Nepalese society, political empowerment is slowly being recognized but still presents barriers to sustainable change. Nevertheless, their study provided confirmatory evidence that small-scale commercial hospitality businesses do act as a vehicle for the sustainable empowerment of women.

The second example of successful female entrepreneurship in Nepal is the Three Sisters Non-Government Organization (NGO). Empowering Women of Nepal (EWN) is a non-profit company, based in Pokhara, which aims to improve the lives of Nepali women and girls through adventure sports and tourism. It was founded by three Nepali sisters, Lucky, Dicky and Nicky Chhetri, who were pioneers in the promotion of female trekking guides in the Himalayas. Upadhyay et al. (2011) reported that women from Three Sisters enthusiastically strived to extend themselves, their realities and their contexts through the means of tourism supply. As a result of participating in the Three Sisters NGO, women came to know about instruction in health, sanitation, First Aid, English, self-advancement, life competencies and the likelihood of learning about the natural world, including travel in their community districts. Many females have pursued and acquired high-quality expertise in various roles in Nepal's trekking and guiding industry. Acharya and Halpenny (2013) maintain, "women have been inactive in community affairs due to institutional, socio-economic and cultural constraints. These affairs have remained in the domain of men in Nepal. However, the processes of modernization and globalization increased awareness to women, and they play a vital role in community affairs, particularly in achieving community security, development and progress", as evidenced in the examples described above. 


\section{Education, labor markets and vocational education and training (VET) in Nepal}

Even though there has been an extended history in long-established and unofficial skills training, Nepal has had a short history in recognized skill training. It is commonly agreed that recognized skill training commenced with the founding of a solitary technical institute in 1942 for providing substitute superintendents (Sharma 1987). In 1929 an Ayurvedic school was founded in Kathmandu which prepared ayurvedic clinicians to be certified as Vaidya. In 1934 a public medical school was founded to deliver instruction for compounders and dressers (Ramse 1992). In 1960 Nepal tried to occupationalize its education structure through the Basic Schools based on the Gandhian beliefs of fiscal self-dependence (Karki 2010; Sharma 1987).

Multi-function schools were launched in 1961 and offered vocational curricula in food production, trade skills, clerical science and home economics as sanctioned by the National Education Planning Commission. These schools were transformed into vocational schools under the New Education System Plan (NESP) in 1971. Over 120 jobrelated schools were functioning, advancing vocational guidance mostly in agrarian, trade, and commercial vocations by 1979 (Karki 2010).

In 1979 the National Education Committee initiated a Technical School Work blueprint. The Technical School Scheme stressed skill preparation and occupational training of those who failed to complete school, those who had already left school and those not going on to university, incorporating the financially impoverished populace who are unable to pursue higher education. Following many proposals, under the Technical Education and Vocational Training Act, 1989 the Council for Technical Education and Vocational Training (CTEVT) for directing, advancing, and fortifying Technical and Vocational Education and Training (TVET) in Nepal was founded (Karki 2010).

In contemporary times, the education system of Nepal has been undergoing change since 2009 through the implementation of two educational reform plans. The objective of the School Sector Reform Plan was to improve students' access to quality education. Quality is defined as education that, "satisfies basic learning needs, and enriches the lives of learners and their overall experience of living" (UNESCO 2000, p. 17). The multi-faceted reform targeted a range of aspects of the Nepali education including VET. It argued for the inclusion of Vocational Training within schools and an increase focus on provision of training skills viewed as 'soft'. The current reform, the School Sector Development Plan 20017-2023. It proposes a bold structural shift whereby the aim for VET is "to strengthen technical and vocational education in secondary schools by introducing measures that develop qualified and technical human resources capable of earning decent incomes". The plan to achieve this is to "introduce a broad National Vocational Qualifications Framework to accredit institutions that deliver vocational education" (p. 8).

In an analysis of VET programs in Nepal, the literature is not particularly positive, and even less so in regard to women's access to further education and training through the VET system. In a broad analysis of VET education across Asia, Agrawal (2013) argued that characteristics of the sector include low employment, high drop-outs, poor quality of teachers, inequitable access for women and rural populations, limited private sector involvement and budgets. An analysis of Nepal's labor market and migration trends demonstrate that the VET sector is currently fragmented (Bandita et al. 2015). Different 
stakeholders, including government, private sector, donor agencies and NGOs, provide skills training without coordination (Agrawal 2013). As a result, Nepali VET centers face low pay rates, poor attendance of some students, low standards of literacy and living conditions in rural contexts, working conditions inequitable for females and a lack of resources (Koirala and Dhungana 2015; Shrestha 2011). Hofstetter (2014) discussed the VET industry as an uncoordinated approach hampered by rapidly changing technology training requirements, instructors who are not industry-experienced, and not targeted soft skills like trainees' abilities to work in teams, attitudes, honesty, and work discipline. He specifically mentions the lack of pedagogical training, competency-based training, highly theoretical approach and little or no industry experience in instructors as some of the significant deficiencies in the current VET offerings. This is an issue widely experienced throughout the Nepalese education system. Indeed, much of the learning in Nepal is rote based and relies heavily on textbook regurgitation (see Ham 2018). An overview of the subjects offered at various VET centers and show offerings of Cookery and Hospitality.

Similarly, Kusago and Phuyal (2009) indicate only one Food and Technology course, total enrolments 40, offered at a single public VET site compared to 126 Health and 33 Engineering courses offered at the same site in 2005. At the time of writing this paper, the situation is much the same. In this context, the women who participated in this research could not access suitable training in the VET system of Nepal partly due to the inadequate offering of the VET course in their context and the barriers inherent in their status of disabled or marginalized women.

Certain Nepali universities still offer TVET curricula especially at a Diploma or skill level which have an admission volume of 1520 students (CTEVT 2010); while this figure is about 10 percent of the overall admission volume at the Diploma or certificate level in Nepal. Tribhuvan University oversees a Diploma level program in Engineering and Forestry and a certificate level program in health science. Kathmandu University, the National Academy of Medical Sciences, and the B.P. Koirala Institute of Health Sciences have also been running a certificate level course in nursing (Karki 2010).

\section{Overview of the research design}

The research project's design was in response to an invitation to develop training to improve the skill level of the women managing and operating the cookery school for tourists. The five women selected to participate in the training showed a special interest in cooking and tourism and were already working within the school. A co-educational design was considered the most culturally and socially sensitive situational response for educating marginalized women. In this research, co-educational design means a collaboration of teaching and learning design between the female researcher/educators and the women in the cookery school.

The challenge to women entering the hospitality and tourism sector, as outlined previously, established a complex of social and cultural factors. These factors contributed to complicated ways that exclude women in Nepal from the right to and access to appropriate education within the Nepali social and political environment. To overcome these barriers, the initial discussions with the Seven Women Social Enterprises' Australian and Nepali CEOs established two goals for the project: 
1. short term rapid increase of the employed women's skills to provide an exceptional cooking school experience for tourists, and

2. an appropriate ongoing culinary training program for women with the long-term intention of creating an accredited training facility for women to enter the Nepali hospitality sector.

The outcomes of these goals are the subject of this current paper and discussed throughout.

\section{Bernsteinian approach to education and empowerment}

The researchers employed a Bernsteinian theoretical lens to frame an understanding of access to educational knowledge. From this perspective, schooling aims to enhance knowledge boundaries and create confidence at an individual level (Bernstein 2000). In our research, schooling means a site, space or place where students gather to learn/ experience and teachers instruct/guide/coach-in this case, a cookery school. Bernstein differentiates pedagogic equalities into rights, conditions and levels (Bernstein 2000). Observing the rights of the learner include enhancement, inclusion and participation. When these rights are acknowledged and enacted, conditions of confidence, communitas (a sociological term meaning spirit of community built on shared goals), and participation in civic discourse may be enabled (Hearn 1980; Turner 2017). Individuals empowered by knowledge and confidence are more likely to have a voice at individual, social and political levels. Participants in our study came from circumstances of extreme disadvantage; in the context of a cookery school as a site of schooling, the individuals within Seven Women have severely diminished educational rights. Within Seven Women, the educational rights of these disadvantaged women are acknowledged and, importantly, acted upon positively to create a space and communitas to build knowledge and confidence.

\section{Methodology and method in phases}

Bricolage is an approach to qualitative inquiry that enables researchers to intuitively use their unique exposure to various theories and methodologies to inform their research. Each researcher brings a suite of specialized tools to the research toolbox. According to Kincheloe et al. (2011), the bricoleur-as-researcher understands that they cannot rely on mono-logical knowledge to inform a complex problem. Hence, researchers tinker and weave their specialized research tools to construct a rich tapestry that best depicts the research.

Pragmatic researchers generally work under a pluralistic assumption that does not favour one system of philosophy or reality. Instead, a merging of pragmatism and bricolage allowed the researchers to choose non-traditional approaches to research and understand that their participation in the study has consequences (intended and unintended) (Bernstein 2000; Creswell 2003; Kincheloe et al. 2011). Furthermore, as researchers, educators and participants, the researchers reconciled seemingly alternative knowledge claim systems. Therefore, the research employed bricolage as a methodology to enable reconciliation of confirming and conflicting perspectives, which ultimately contributed to a richness of the research (Deagon 2015). 
Traditionally rigid methodology, such as early forms of grounded theory (Charmaz 2006) or qualitative surveys, coded data, and objective observations are inappropriate given the closeness with which the researchers worked with the participants. Bricoleurs assert the rigor and validity of their research by viewing a problem from multiple perspectives using several tools at their disposal to locate convergence in themes and findings. The methodological approach considered the researchers' emancipatory, feminist and empowerment perspectives to education and women's studies. The research did not occur linearly; rather, through Participatory Action Research (PAR) stages. McIntyre (2008) identified how the PAR focuses on "the active participation of researchers and participants in the co-construction of knowledge; the promotion of self-awareness and critical-awareness that leads to individual, collective, and/or social change; and the building of alliances between researchers and participants in the planning, implementation, and dissemination of the research process". PAR changes the role of participants from 'subjects' or 'objects' of a study to 'agents' (Denzin and Lincoln 2011) to co-researchers who are actively involved in each stage of the process from initial framing of problems, identifying solutions and translating findings into actions within their communities. As Kindon et al. (2007) explain, PAR changes the research approach from one based on hierarchical relationships between research and action, and between 'researchers' and 'researched', to one in which researchers and members of the community collaborate to examine the problem and bring about deliberate change. The researchers assert that they acknowledged ethical considerations and were aware of political agendas to empower the marginalized women. The researchers were not passive observers (Koirala and Acharya 2005; McMillan et al. 2011). Indeed, once we conducted initial observations and noticed that the participants demonstrated initiative, we encouraged the participants to become active co-constructors of the cookery school training experience.

\section{Ethical consideration and PAR cycle}

Ethical clearance was granted under protocol Recontextualizing Australian cookery education for a Nepalese context Project Number H17/02-015. Five participants were invited to contribute through the provision of consent to participate in and withdraw from research information in both English and Nepalese (written and verbal). All women consented to participate. The research was conducted in six phases, each containing a PAR cycle of observation, reflection, plan and action (Denzin and Lincoln 2011): source, explore, identify, implement, consolidate, and evaluate. At each phase, reflective practice and sharing of ideas and considerations were a collaboration between the women, researchers and data. As per the bricolage approach, the collection of initial data included Nepali educational policy written in English, HITT Training Manuals, photographic, audio and video recordings, researcher field notes and observations, and for evaluation purposes, observations of workshops and follow-up interviews with participants. In addition, consultation occurred between the researchers, the CEO and the In-Country Director seeking clarification and confirmation of actions and activities before the designing and beginning of a new cycle of action. 


\section{Framing the unique Seven Women context}

An investigation into the situational context and progression of the Seven Women Social Enterprise was sourced directly from the Australian CEO and the Nepali InCountry Director. The CEO and Director provided a comprehensive description of the centre's purpose and specifically the cookery school. Within the initial phase of discussions, they outlined the main problem under investigation: how to upskill the women to have qualifications for both short- and longer-term destinations. In the short term, the women needed skills that would allow them to work effectively and safely in the tourist cookery school, but in the long term, desired certified qualifications to allow them access to employment in other business ventures in the organization or gain access to the Nepali hospitality industry. They explained the context of Seven Women as:

...established 15 years ago in response to the plight of a group of marginalized [sic] women who were outcasts in their society... Seven Women began on a small scale when a traveller [the Founder of Seven Women] met seven disabled women living in a tin shed in a back street in Kathmandu. Rather than give money to those women, Seven Women was born out of an empowerment approach to support self-determination for these women to learn new skills and earn an income leading to long-term independence for them and their families. The empowerment approach has led to a significantly different outcome from many charities in Nepal, which have followed the tradition of aid in the form of welfare which has ultimately led to dependence and has not allowed beneficiaries to prosper. [CEO Australia, email communication, 16 November 2018]

The CEO then explained how the social enterprise grew through identifying the expressed needs and wants of the women, together with creating opportunities for the women to participate in the hospitality and tourism sector:

... the first step towards equipping the women with the ability to read and write and understand numbers. This was a crucial first step before learning new skills: how to earn and save money follows later. The business model employed by the organization has been one of creating enterprises, which operate in sectors where there is a need for well-trained staff members, such as with hospitality and culinary skills, and where there is a market need and gap for tourists. [CEO Australia, email communication, 16 November 2018]

Prominently displayed on a wall banner in Seven Women's Kathmandu Centre, their Model of Development consists of seven stages:

1. Identify need

2. Find/build a facility

3. Create a management team

4. Skills training and employment

5. Education and development

6. Partnerships and expansion

7. Phase-out [foreign input] once sustainable 
Our research project situates within the fourth and fifth stages of their development model to provide training and education opportunities for the participants with a view to employment and expansion.

Our organization has grown through partnerships with tour companies, connecting people to its businesses through its own tour company and embracing responsible tourism and partnerships with other local NGOs. It has also aligned with global brands, such as Rotary, which has helped spread the word. [CEO Australia, email communication, 16 November 2018]

The context of this research was to formalize the education and increase of capacity of five key women who were running a boutique cooking school for tourists with a view to the social enterprise expanding to include a small hotel with a café. It was envisaged that these five women would not only run these two tourist ventures, but provide ongoing training to new women, firstly as a provision of skilled workers for the social enterprise, but with larger vision for employment in the wider tourism industry in Nepal. The participant group is small, but the five women selected for participation in the research constituted the entire hospitality staff of the cooking school which was, as that point, running daily classes with up to 20 participants in one of two kitchens. The original kitchen was a small room in an upstairs section of the Seven Women center. That kitchen's capacity safely accommodated appropriately five tourists and one trainer. As their tourist cookery school grew, a new kitchen was constructed. The new kitchen accommodates up to 20 tourists (sometimes more) with two women facilitators and two or three other women washing dishes in an outside dishwashing section. Over the 18-month research period, it was not uncommon for the women to be facilitating the cookery lessons for tourists twice daily, six days per week.

The research project required the researchers to investigate the VET opportunities and requirements for certification in Nepal. The purpose of this was to ascertain the training curriculum and facilities required for a formal Hospitality qualification that would satisfy international cookery standards. To achieve this aim, the qualifications and experience of the researchers are paramount. To explain, one of the researcher/teachers is a trained Home Economics professional and registered Secondary School Teacher who now trains pre-service teachers in cookery and kitchen management. Her work also sits in the Australian VET Hospitality space, and she is cognizant of the VET Hospitality curriculum, assessment and policy requirements. The second researcher/teacher is also a trained Secondary School teacher who has taught in cross cultural contexts with a range of curriculums and pedagogical approaches. Her PhD research was based on the Nepali Education reform which enabled her to understand and address the way the women expected to learn, and how to make changes and contextualise the learning experiences of a practical nature within the training. Finally, the third researcher has worked in Nepal with numerous women's organizations and tourism operators for 15 years. She has also published widely on women, entrepreneurship, empowerment, and the effects of patriarchy on Nepalese women within the hospitality and tourism sectors. Our combined experience allowed us to interpret and recontextualize the necessary curriculum for the Nepali women's unique context. With this insight, we strategized the women's training needs and most appropriate pedagogical approaches. 
As part of the curriculum development process, we analyzed the Australian VET Certificate of Hospitality I, II and III modules for content comparison. To become a qualified chef in Australia, progression through the Certificates in Hospitality would equate to 4 years' full-time study with significant requirements of supervised practical training, exposure to a range of specialized equipment, and formal practical and theoretical assessment (Wardle 2014). Comparatively, the knowledge, skills and content required to become a qualified chef in Nepal equate to an Australian qualification as both require 4 years of full-time study under supervised conditions and significant practical assessment in a commercial kitchen. We concluded that for the women to undergo formal qualifications in cookery without access to a suitably equipped commercial kitchen and in the current climate of discrimination and marginalization of women, formal qualifications are currently unrealistic.

Consequently, a needs-based approach to the provision of cookery training ensued. To this end, the researchers located an informal VET-based cookery course from the NGO High Impact Tourism Training (HITT) for training for jobs and income program implemented by an international NGO within Nepal. These informal modules (hereafter referred to as "the manuals") were freely available on the internet, written in English, and translated into Nepali. The information the manuals contained had been sourced from a western certificate level course, recontextualized to Nepali cooking and kitchen conditions, and aimed to train Nepali people to work in hospitality contexts catering to a western-style tourist service. The writing group of HITT granted permission to the researchers to utilize and adapt these open-access manuals. A collaborative decision was made between the CEO, women and researchers that, given the short timeframes for training, the HITT manuals would not be implemented using a traditional VET structure; instead, utilized as checklists of essential skills to guide the researcher/teachers design of a "made to fit", needs-based training response.

\section{Industry perceptions of women workers in the Hospitality sector}

The PAR "source" phase outlined above occurred before the researchers arrived in Kathmandu. Once in Kathmandu and the physical presence of the participants, the researchers spent time exploring their environment to gain a thorough understanding of the women's needs, strengths, limitations and cultural context. Acting as both observers and participants, researchers spent several days interacting with the women in the center and visiting various other Hospitality contexts. Immersion provided us with a comprehensive view of the specific needs of the women and center staff and an appreciation of the objectives and values embedded in the Seven Women's program to guide the development of values-aligned training.

The PAR phase of "explore" consisted of interviews with existing Hospitality industry trainers, observations of and interviews with the women participants, researcher participation in cookery classes with other tourists, and visits to restaurants and hotel kitchens in the tourist area Thamel, Kathmandu. Visiting a range of Hospitality establishments beyond the Seven Women center facilitated a deeper understanding of the barriers and requirements to training women in the Kathmandu Hospitality sector. Although a progressive male employer, one hotel manager interviewed stated that ultimately, he does not like to employ women because of a perceived lack of confidence in the kitchen. $\mathrm{He}$ 
stated the attributes required for employment in the hotel kitchen included literacy at a Plus 2 (Senior Secondary school) standard, impeccable personal and kitchen hygiene practices and interestingly, he stated:

...then I think... they have to love what they are doing... they have to be fascinated about it [cooking and the kitchen], because you know, to be in the kitchen, the stress and then, you know, and focus... It's a dangerous area there, you know?... Oil and fire and this and that. Yeah, so I would say basic education, hygiene and then their focus and their-like desire to be in the kitchen. (Hotel Manager, Thamel, 3 May 2017)

He then stated that women are generally timid and lack initiative, so they did not fit the required criteria. He also stated that some women are not allowed in the kitchen at all because of their caste. His comment implied an exclusion of all of the women from the organization not being allowed to enter the hotel kitchen because of their caste and/ or disabilities. As stated previously, this hotel manager was a progressive and culturally sensitive man and was aware and proud of the work that the Seven Women was doing in Kathmandu. Despite this, he was forced to conform to cultural norms. Thus, women employees working in the hospitality industry must be selected from higher castes because the lower caste is considered unclean and unhygienic (see Bhandaree et al. 2013). For these reasons, lower caste women are not seen or encouraged to work in food preparation and consumption areas. Consequently, this revelation eliminated any commercial kitchen in Kathmandu as a potential external training provider for the organization's women. Until this situation is challenged and changed, in-house training is the only way to provide a safe and supportive learning environment (Nightingale 2011).

\section{Culturally embedded ways of thinking}

Regarding a perceived lack of women's confidence and initiative in commercial hospitality establishments in Kathmandu, there is a culturally embedded way of thinking of not wanting to disappoint. Therefore, a person who receives instructions but does not understand the instruction will not ask for clarification from the person giving the instruction. They will either; not do the job at all and walk away, or do the job incorrectly and "get into trouble". One hotel manager interviewed believed that retention of female staff was difficult for this reason. Often, to save face, a trainee will just leave an establishment rather than go back for what they perceive as humiliation. This disjunct between a curious learner and a culturally appropriate response to failure is a difficult one to overcome. Curiosity and the ability to ask a supervisor or employer questions are required personal attributes in a Western learning environment (Jack et al. 2010). One hotel manager believed that girls who have received education from foreign service providers (Australia, China, Switzerland, India) may be more inclined to ask questions and persist with training. In contrast, females with little exposure from foreign sources of education may perpetuate unhelpful learning behaviors because of compliance with cultural norms and saving face.

To summarize, gleaned from the interviews with three male hotel managers, we identified that male hotel managers do not employ Nepali women because of a perceived lack of demonstrated confidence and initiative; caste is a significant barrier; and employers 
look for desired personal attributes (male and female) of curiosity and passion for cooking (McMillan et al. 2011). These perceptions of employees relate directly to the women participating in current and future employment in the hospitality industry in Nepal. Furthermore, sourced from the participants and confirmed by the literature, violence toward women in the workplace, caste and/or social status, single motherhood, and pervasive negative perceptions of disability compound employment barriers for the women (Dhakal 2008; Hatlebakk 2008; Jack et al. 2010; Ministry of Health and Population 2012; Nightingale 2011; Upadhyay et al. 2011). Consequently, the wellbeing and physical safety of women is paramount.

\section{In-house training needs}

The PAR "explore" phase continued with observations of the women's skills in the cookery school over 3 days to establish the participants' strengths. The PAR “identify" phase concluded that these strengths included: an ability to demonstrate existing cookery skills, enjoyment of cooking and working in the kitchens with tourists, and a desire to train new women arriving in the center. The training needs of the women were identified as:

- Personal hygiene knowledge and skills

- Hygiene in the kitchen

- Food safety-cross-contamination and food storage

- Washing dishes with soap and hot water (problematic)

- Laundry-clothes, aprons, dishcloths

- Knife skills

- Lack of equipment and use of equipment-measurements: scales, cups, teaspoons, tablespoons

- English words for specific cookery terms and procedures

- Gaining confidence with speaking English and talking to tourists

After consideration, the women's prior knowledge included several basic cookery skills; however, in terms of equivalency to entry-level Australian Hospitality skills and knowledge, the women lacked an understanding of hygiene procedures, cookery skills, ingredients and equipment suitable for formal certification. By comparison, Australian school-aged children are explicitly taught personal hygiene from a young age and usually have access to a well-equipped kitchen with numerous utensils and ingredients. As evidence, a half-day personal and kitchen hygiene training session was conducted by the In-Country Director with all the women in the center.

The key themes covered in this training session focused on:

1. Frequent use of antiseptic soap to wash hands

2. Keeping hair clean and tied back

3. Avoiding spitting, sneezing, nose picking

4. Not sharing eating utensils with other people (including children)

5. Cleaning clothes and aprons regularly

6. Female gender roles and cultural expectations 
In Nepal, women, especially those in remote villages or from extreme poverty such as the homes of the research participants, have limited access to water, sanitation, a minimal array of utensils, and the ingredients available are only those locally sourced and therefore shared and not wasted (Central Intellegence Agency 2019; Jaffee et al. 2018). Thus, cookery skills and basic hygiene required by the hospitality industry are not embedded as an everyday part of the "life at home" routine for most women and girls. For those privileged with public education in Nepal, not all students would receive explicit and frequent personal or kitchen hygiene training (as is embedded in Australian education institutions from an early age) due to lack of amenities, knowledge and resources. Seven Women has added a level of complexity to the women's knowledge and roles by also exposing them to interactions with tourists.

Another identified challenge for the women was the way they interacted with tourists in the kitchen. The role of the cookery school instructor required the women to give safety, hygiene and cookery instructions to the tourists, with an expectation that they had to "entertain" the tourists with stories about their lives and explain the dishes origins and significance. Further discussion with the women showed that they did not understand this role and lacked the confidence to interact in such a manner. This stemmed partly from their lack of confidence in using English but also from the culturally embedded "servitude" roles and caste, particularly concerning their interaction with men. Interacting confidently with international audiences was identified as a challenging task for the women. In addition, the researchers also identified that the traditional methods of 'learning' in the Nepali context focused on theory and rote learning, which differed from the practical teaching methods employed by the Western researchers who trained in the kitchen.

\section{Implementation of training}

With a clear understanding of the context, and with a completed analysis of the HITT cookery training manuals, while training was occurring between researchers and participants, a purposeful decision was made to limit the women's access to the manuals during the PAR "implement" cycle. The justification for this was that they had expressly requested access to the manuals so they could 'learn' the information and in the Nepali culturally accepted style of rote. To this end, the researchers enacted a different approach to the reproduction of knowledge and skills that focused on the development of skills in situational learning and encouraged the women to question and express their cultural expectations of a woman's role in the kitchen (Koirala and Acharya 2005). The PAR approach saw the women and researchers work together to train each other through a process of cultural and industry expectations and skills exchange that then fed into the emerging roles in the implementation of this phase.

Table 1 outlines some of the main identified issues experienced by the women, the type of targeted training provided, and the outcome observed as a result of targeted training. As described in Table 1, the key identified issues with early cookery school experiences with tourists were moments of silence, bossiness or "taking over" tasks, difficulties in giving instruction and checking for understanding, and safe kitchen practices. 


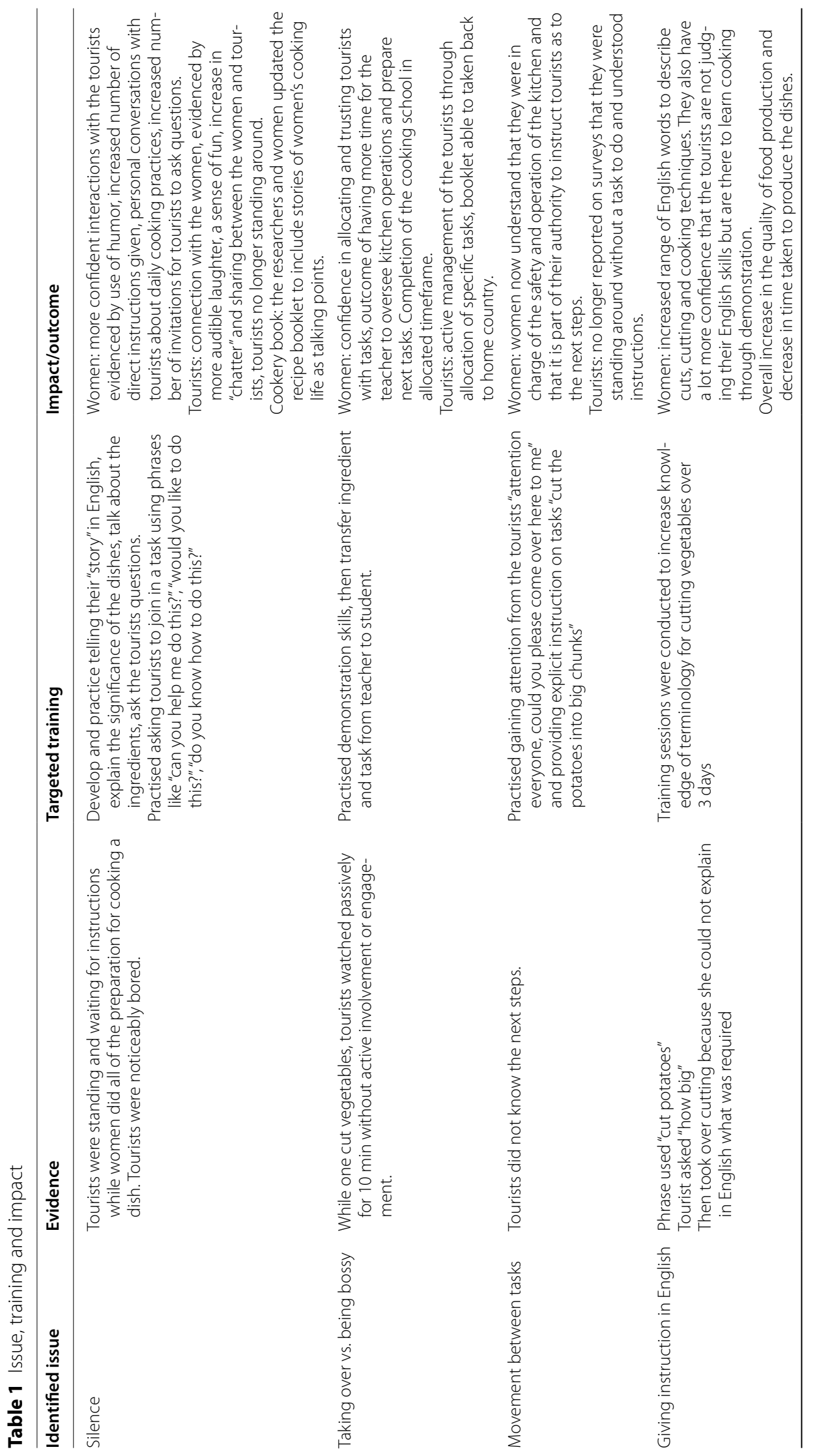




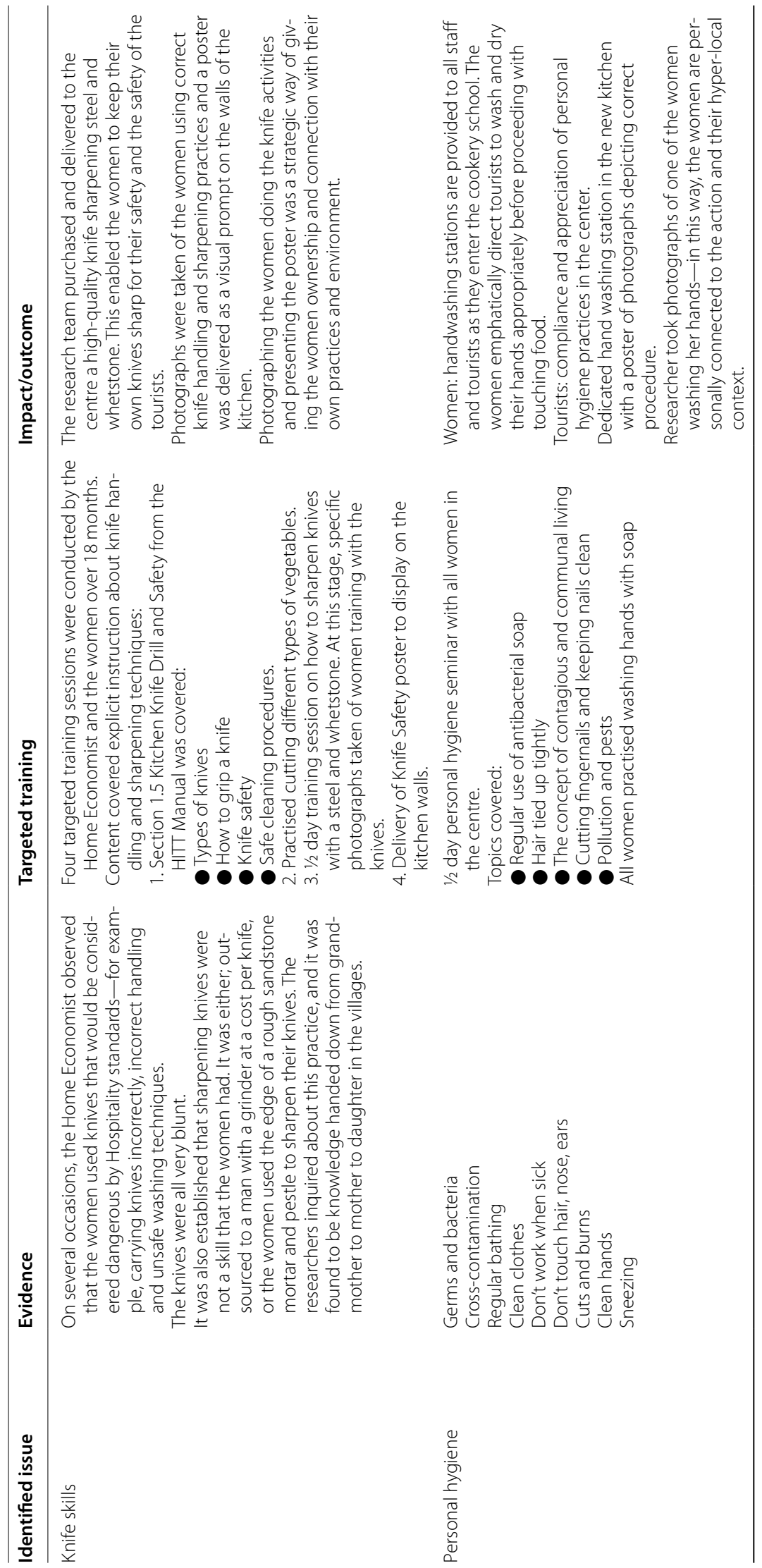




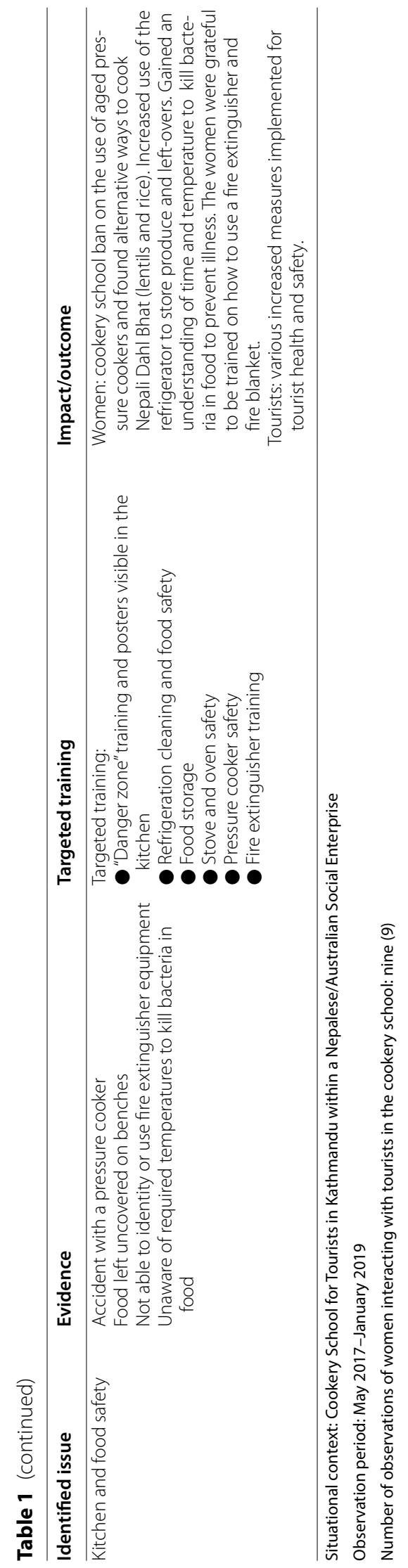




\section{Consolidation of skills and understanding gained}

On returning to Australia, the researchers were able to supply resources that were not able to be sourced economically in Nepal. These resources, including copies of segmented training manuals, have subsequently been delivered to Seven Women through visiting staff and tourists. The women have consolidated their training through their ongoing implementation of cookery school classes and follow-up training with the researchers on successive visits to the Seven Women kitchen. The outcomes of the targeted training are encouraging. The women have demonstrated retention of key skills and knowledge. Their confidence in their interactions with the tourists has increased. The women who are frequently selected to work in the kitchens with the tourists are more confident in delivering a safe and entertaining cookery experience.

\section{Discussion}

\section{Challenging roles}

According to Acharya and Halpenny (2013), there has been a separation between the roles of women and men in Nepali community and particularly within the business arena where women have been largely excluded. In the context of this study, the women were also in a duplicitous position in that their involvement in the cookery school aligned with the traditional role of women whose place was in the kitchen; however, this kitchen context required them to train other women and interact with tourists who are paying customers in a business transaction. The women were not aware that this changed the role they were required to play, and in some respects, the two roles were in opposition to each other. They lacked the confidence, and in some cases, skills and awareness of the need to move from food preparer to modeler of food preparation; from active participant to supervisor of active participants', and enactor of instructions to provider of instructions. Figure 1 is a visual representation of the complex factors that influence roles, responsibilities and relationships of the Nepalese women participating in the organization's cookery school enterprise. It is important to note that the women are paid by Seven Women to facilitate the cookery school for tourists. Payment for employment challenges a traditionally male role of providing financial support to the family.

Several actions were taken by the research team to assist the women in making an ideological shift in understanding their complex roles and responsibilities of working in the kitchen environment. For example, the cookery expert researcher conducted training for the women that focused on safety and hygiene-two of the identified areas of skill training required. She explicitly modelled the way to interact with learners and non-experts in the kitchen. The women were then directed to copy her style of interaction with the research team, who took on the roles of non-experts. The women were also immersed in role-play scenarios where the research team took on a range of roles, specifically under the guise of international tourists. Throughout the whole project, the researchers interacted with the women using every opportunity to play games, discuss and acknowledge their backgrounds, and create a sense of fun and sharing as a community of learners. The element of fun was important both to challenge the existing subservient approach of the women and to model the creation of relationships based on equity and humor. 


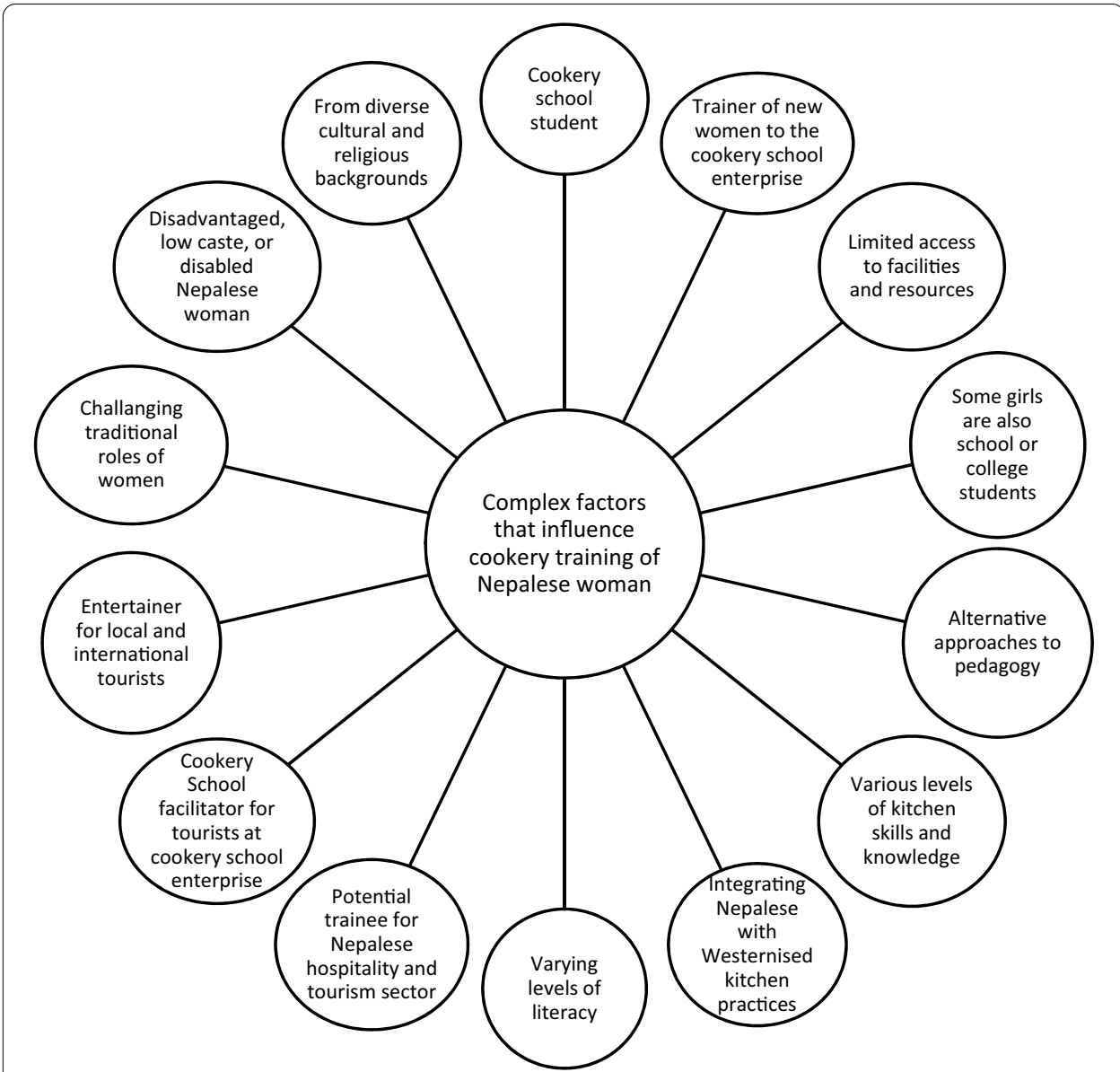

Fig. 1 Visual representation of the complex factors that influence roles, responsibilities and relationships of the Nepalese women participating in the cookery school enterprise

\section{Changing pedagogy}

Two of the researchers are qualified Australian school teachers. Pedagogy is understood in the teaching profession as the art and science of teaching and learning. The literature review outlined that the teaching methods or pedagogy used by instructors in the VET system in Nepal rely on traditional theory-based and rote learning pedagogy with little to no practical classes (Agrawal 2013). This description of teaching practices is common throughout the educational profession of Nepal (Bista 2011), including Primary and Secondary schools (Lohani et al. 2010). The women in the center had not accessed VET settings for training. Their expectations of educational instruction align with the process of rote learning as opposed to practical experiences as the prominent form of training according to their Nepali culture (Ham 2018). This was evident when the participants requested to take home the manuals so they could 'study or rote learn' the information. A decision was made by the researchers to challenge the expected and accepted format of learning. It was observed that the Nepali women's preference for this style of learning resulted in them undervaluing their existing skills in preference for those they thought they could gain from written print. To foreground the women's existing skills, the educator-researchers did not utilize the manuals within the classroom, instead instructed the 
women through practical cookery sessions similar to those utilized in training institutions in Australia. By negotiating with them to conduct training in a practical way that differed from their expectation, made the participants also reconsider their cultural assumptions and their skills within the cookery space. To extend these concepts, the researcher, who was not a specialist in cookery, conducted a training session that introduced the women to sustainably sourcing their own training needs in the absence of 'experts'. YouTube was used to instruct the process of cooking pizza on the stove, which challenged the mindset previously held that it was impossible to cook pizza without an oven. The educator-researchers modelled problem-solving, finding and creating solutions to overcome existing barriers.

It has been established that literacy is a significant barrier for underprivileged Nepalese women. Therefore, a secondary purpose for deciding to limit the participants' access to the printed manuals was that, in the future, the research participants would be required to train new women to the center. These new women may or may not be sufficiently literate to read the manuals in English or Nepalese. It was anticipated that modelling the practical approach to teaching and learning would provide these future trainers with skills and approaches that they could utilize in their peer-to-peer training roles (Posner et al. 2009). Finally, the further factor influencing the decision to reject traditional Nepali learning approaches was because of the type of content. The information was almost entirely based on practical application, which is only useful if applied in a kitchen or cookery context. The traditional approach to Nepali learning would not have assisted the women's ability to extend their skills and functioning in the kitchen.

\section{Creating confidence}

Initial findings indicated that the hands-on participatory approach to teaching, learning and research conducted in a kitchen environment was an effective tool for empowering the women and improving their confidence to engage with tourists (Hillman and Radel 2021; Guinée 2014; McMillan et al. 2011; Scheyvens 2000). As active participants in their training, the PAR approach encouraged individuals and group inquiry about knowledge and skills that they considered effective and interesting to improve their operation in the tourist business. For example, initially, the participants in this study were not aware of the model or purpose of cookery classes from the point of view of other international contexts. Stemming from group discussions, they were not aware of the fact that people, including men, desire to be taught how to cook in a Nepali style. This was a surprise to the women. With this knowledge, throughout the training conducted, the women responded positively and enthusiastically to men being included in the cooking class. The result of a seemingly simple group discussion was that their confidence while interacting with male and female tourists increased. This flowed on to an increase in participation and enjoyment from the tourists.

McMillan et al. (2011) asserted that economic, social, psychological and political empowerment (four domains model) were impacted positively when women actively participated in commercial hospitality activities. They state that "somewhat ironically... the traditional roles which had once been the cause of their marginalization [soft skills and "female" skills of cookery and household caretaking], have now become the root of their empowerment" (McMillan et al. 2011). The evaluation follow-up on the women's 
progress 18 months later indicated that their confidence and enjoyment of cooking with tourists had increased, and they had become more willing to share their knowledge and mentor new women to the cookery school.

An additional element impacting the women's confidence was their skill level of English. The women were hesitant to interact in English with their tourist clientele, and this impacted their willingness to engage as facilitators in the cookery school. However, discussions with the clientele revealed the women's expectations of themselves were higher than the tourists. English words for skills and utensils then became a focus for the training program, and proficiency was easily gained through their hard work and ongoing work with the trainers. The biggest barriers were the incidental questions that they predicted or feared tourists would ask. They expressed fear of being in a situation where tourists were asking them questions beyond the cooking, and they would not be understanding or be able to assist. To combat this, the researchers brainstormed strategies that the women could respond with until a solution could be worked out.

\section{Conclusion/recommendations}

There are three sectors for which the findings of this research have significance: the women and Directors of Seven Women; the designers and deliverers of training programs; and the wider social construct of Nepal. Our research contributes first steps toward creating a formal hospitality training facility for marginalized women wishing to enter Nepal's hospitality and tourism sector. The investigation into the training required showed that transition from informal to formal qualifications would take approximately five to ten years. Despite this time factor, the research project demonstrated how informal hospitality training did positively impact marginalized women's level of confidence and capabilities and capacity for working in the tourism sector. The Seven Women organization operates within an innovative and sustainable Model of Development, but succession planning is essential. One of the fundamental principles of the women's organization is the gradual removal of foreign intervention and assistance to become ultimately a fully self-sustainable organization run and operated by marginalized Nepalese women and their supporters.

Our research indicates that delivery of education programs must consider hyper-local context and complexity. To achieve this, our paper has presented a model of complex factors that may assist with inquiry and future trainers. Additionally, this research was successful, in part, due to the extended methodological considerations within the PAR phases of sourcing, exploring and identifying and the nature of its co-educational design. Before enacting a sourced, Nepali contextualized training package, the researchers critically analyzed the context and needs and then, in collaboration with the women, decided how best to implement the training. Collaboration facilitated the PAR implementation phase of the training to challenge existing cultural stereotypes and create empowerment beyond being able to act safely in the kitchen (Guinée 2014; Koirala and Acharya 2005). We recommend that designers and deliverers of any imported training package factor into their implementation time to explore their context and identify a range of existing barriers beyond the bounds of their own assumed cultural understandings and assumption. 
The Seven Women organization has expanded operations exponentially, including a new boutique guesthouse opening in the second half of 2019. The purpose of the guesthouse is not only to increase revenue for the center so they can continue to provide scholarships and training for marginalized women but also to provide a safe and supportive working environment for the women until such significant social and cultural change has occurred that Nepal's Hospitality and Tourism industry accept Nepali women as a knowledgeable and skilled resource. The five women we conducted food skills training with, also now work in the guesthouse, and have trained numerous other women. Those five women's skills, authority and confidence has had an ongoing impact for the Seven Women organization.

The social implication of this research is that educated and skilled women are active change agents. Authors such as Acharya and Halpenny (2013), Gurung (1995), McMillan et al. (2011), Scheyvens (2000), Upadhyay et al. (2011) all established that foreign development groups have championed Nepali women to encourage their selfassurance and become actively occupied in tourism and hospitality spaces by way of active participation and delivering training and coaching. In this regard, it is recommended that ensuring succession and sufficient numbers of adequately trained female hospitality trainers, foreign educational assistance, such as the one described in this paper, will remain necessary until education reforms are taken seriously by the Nepal Government, and gender equality is realized, and caste and disability are de-stigmatized. As a ray of hope toward realizing these meritorious goals, participation in cookery skills training was a catalyst that improved confidence, communication skills and exposed women to possible avenues toward self-sustainability, emancipation and empowerment within an often-hostile working environment for women from severely disadvantaged backgrounds in Nepal.

\section{Limitations and future research}

Sustained positive social change takes time. The small group of five participants involved in an initial 2-week training period, and five further visits by some of the researchers over 18-months to conduct follow-up training and evaluation was not sufficient to generalize on the impacts of the training program. In addition, our research project was not the only education program the women were receiving. The Seven Women organization in conjunction with Stephanie Woollard's Hands on Development tourism company, actively encourage tourists to come and share expertise with the women working and being trained at the Seven Women center in Nepal. For example, tourists have shared their skills in hairdressing, building and construction, food safety, gardening, hotel operators, clerical, sewing and craft. Skill sharing is actively encouraged by Seven Women and Hands on Development for dual purpose: to give tourists the feeling of participation; and to encourage broad skill sets of the women and provide opportunities for growth and development. With this in mind, a longitudinal investigation of the potential for informal hospitality education as a tool for social change and empowerment of marginalized Nepalese women is recommended. 


\section{Acknowledgements}

The authors wish to express their sincere thanks to Stephanie Woollard OAM, Anita Kerr and the participants in this study for their contribution to the data collection process in Nepal.

\section{Authors' contributions}

We confirm that all authors have approved the manuscript for submission. JD, MH and WH conducted data collection in Nepal. JD and MH facilitated the cookery training. JD and MH analysed the data collected. JD, MH and WH collectively wrote the manuscript. All authors read and approved the final manuscript.

\section{Funding}

\$14,285 AUD CQUniversity New Staff Researcher's Grant. The funding body did not have a role in the design of the study and collection, analysis, and interpretation of data or in writing the manuscript. For the remaining funds required to conduct this research, the researchers self-funded.

\section{Availability of data and materials}

Not applicable.

\section{Declarations}

\section{Ethics approval and consent to participate}

Ethics was approved via Australian National Ethics Application H17/02-015/0000020495 entitled "Recontextualising Australian cookery education for a Nepalese context". All necessary consents and approvals have been applied, reported and adhered to.

\section{Competing interests}

The authors declare that they have no competing interests; however, do have a vested interest in empowering severely marginalised Nepalese women.

\section{Author details}

${ }^{1}$ School of Education and the Arts, CQUniversity, Rockhampton, Australia. ${ }^{2}$ School of Education and the Arts, CQUniversity, Cairns, Australia. ${ }^{3}$ School of Nursing, Midwifery and Social Sciences, CQUniversity, Rockhampton, Australia.

Received: 16 August 2020 Accepted: 14 August 2021

Published online: 23 August 2021

\section{References}

Acharya BP, Halpenny EA (2013) Homestays as an alternative tourism product for sustainable community development: a case study of women-managed tourism product in rural Nepal. Tour Plan Dev 10(4):367-387. https://doi.org/10. 1080/21568316.2013.779313

Agrawal T (2013) Vocational education and training programs (VET): an Asian perspective. Asia Pac J Cooperative Educ 14:15-16

Atteraya MS, Gnawali S, Palley E (2016) Women's participation in self-help groups as a pathway to women's empowerment: a case of Nepal. Int J Soc Welf 25(4):321-330. https://doi.org/10.1111/ijsw.12212

Bandita S, Ashim B, Dinesh P (2015) Analysis of labour market and migration trends in Nepal. Deutsche Gesellschaft für Internationale Zusammenarbeit (GIZ) GmbH and International Labour Organisation, Kathmandu

Bernstein B (2000) Pedagogy, symbolic control and identity: theory, research, critique. Rowman \& Littlefield Publishers Inc., Oxford

Bhandaree R, Pandey B, Rajak M, Pantha P (2013) Chhaupadi: victimizing women of Nepal. Scientific Committee of Reviewers. pp 141-143

Bista K (2011) Teaching English as a foreign/second language in Nepal: past and present. Engl Specif Purp World (online Submiss) 11(32): 1-9

Central Intelligence Agency (2019) The World Factbook, Nepal. https://www.cia.gov/library/publications/the-world-factb ook/geos/np.html

Charmaz K (2006) Constructing grounded theory. SAGE Publications Ltd., London

Coyne CJ, Leeson PT (2004) The plight of underdeveloped countries. Cato J. 24:235+. http://link.galegroup.com/apps/ doc/A129016024/AONE?u=cqu\&sid=AONE\&xid=42ade5ba

Creswell JW (2003) Research design: qualitative, quantitative, and mixed method approaches, 2nd edn. Sage Publications Inc., California

CTEVT (2010) A profile of technical and vocational education and training providers. Bhaktapur, Nepal

Deagon JR (2015) "Through the eyes of a satin bowerbird": a bricolage metaphor as an organizing principle for a selfreflective process to explore spirituality in home economics contexts. Vic J Home Econ 54(1):7-21

Denzin NK, Lincoln YS (2011) The Sage handbook of qualitative research. SAGE Publications, Thousand Oaks

Dhakal S (2008) Nepalese women under the shadow of domestic violence. Lancet 371(9612):547-548. https://doi.org/10. 1016/S0140-6736(08)60254-8

Galloway L, Anderson M, Brown W, Wilson L (2005) Enterprise skills for the economy. Educ Train 47(1):7-17. https://doi. org/10.1108/00400910510580593

GFA Consulting Group (2016) Joint evaluation of Nepal's school sector reform plan programme 2009-2016. http://www. moe.gov.np/assets/uploads/files/Joint_evaluation_of_the_School_Sector_Reform_Programme_2009-16_final_ report.pdf 
Guinée N (2014) EMPOWERING women through education: experiences from Dalit women in Nepal. Int J Educ Dev 39:173-180

Gupta J, Cardoso LF, Ferguson G, Shrestha B, Shrestha PN, Harris C, Groce N, Clark CJ (2018) Disability status, intimate partner violence and perceived social support among married women in three districts of the Terai region of Nepal. BMJ Glob Health. https://doi.org/10.1136/bmjgh-2018-000934

Gurung D (1995) Re: Tourism and gender: impact and implication of tourism on Nepalese women. A case study from the Annapurna Conservation Area Project

Ham M (2018) Nepali primary school teachers' beliefs and classroom practices in the context of educational reform. Doctor of Philosophy (Unpublished doctoral dissertation), Central Queensland University, Rockhampton, Australia

Hatlebakk M (2008) Inclusive growth in Nepal. Retrieved from Bergen: http://hdl.handle.net/11250/2474650

Hearn F (1980) Communitas and reflexive social theory. Qual Sociol 3(4):299-322. https://doi.org/10.1007/BF00987330

Hillman W (2019) 'Risky business': the future for female trekking guides in Nepal. Tour Hosp Res 19(4):397-407

Hillman W, Radel K (2021) The social, cultural, economic, and political strategies extending women's territory by encroaching on patriarchal embeddedness in tourism in Nepal. J Sustain Tour. https://doi.org/10.1080/09669582. 2021.1894159

Hisrich RD, AyseÖztürk S (1999) Women entrepreneurs in a developing economy. J Manag Dev 18(2):114-125. https:// doi.org/10.1108/02621719910257639

Hofstetter S (2014) Setting up a fund for technical and vocational education and training: considerations for Nepal. Nadel-Mas Cycle, 2012-14

Jack DC, Pokharel B, Subba U (2010) I don't express my feelings to anyone': how self-silencing relates to gender and depression in Nepal. Silencing the self across cultures: depression and gender in the social world. Oxford University Press, Oxford, pp 147-175

Jaffee S, Henson S, Unnevehr L, Grace D, Cassou E (2018) The safe food imperative: accelerating progress in low-and middle-income countries. The World Bank, Washington, DC

Karki R (2010) National vocational qualifications framework in Nepal. Tech Vocat Educ Train Dev J 1:109

Kincheloe J, McLaren P, Steinberg SR (2011) Critical pedagogy, and qualitative research: moving to the bricolage. In: Denzin NK, Lincoln YS (eds) The SAGE handbook of qualitative research. Sage, Los Angeles, pp 163-178

Kindon S, Pain R, Kesby M (2007) Participatory action research approaches and methods. Routledge, Abingdon

Koirala BN, Acharya S (2005) Girls in science and technology education: a study on access, participation, and performance of girls in Nepal. UNESCO, Kathmandu

Koirala A, Dhungana G (2015) Understanding technical instructors motivational practices in vocational training centre, Morang, Nepal. J Train Dev 1:33-37. https://doi.org/10.3126/jtd.v1i0.13088

Kusago T, Phuyal K (2009) TVET and secondary school education in Nepal: a case study of Hetauda, Makwanpur. Purbanchal University, Biratnagar

Lohani S, Singh RB, Lohani J (2010) Universal primary education in Nepal: fulfilling the right to education. Prospects 40(3):355-374

McIntyre A (2008) Participatory action research (qualitative research methods series 52). Sage, Thousand Oaks

McMillan CL, O'Gorman KD, MacLaren AC (2011) Commercial hospitality: a vehicle for the sustainable empowerment of Nepali women. Int J Contemp Hosp Manag 23(2):189-208. https://doi.org/10.1108/09596111111119329

Ministry of Health and Population (2012) Nepal demographic and health survey 2011. Kathmandu, Nepal. http://dhspr ogram.com/pubs/pdf/FR257/FR257.pdf

Nightingale AJ (2011) Bounding difference: intersectionality and the material production of gender, caste, class and environment in Nepal. Geoforum 42(2):153-162. https://doi.org/10.1016/j.geoforum.2010.03.004

Posner J, Kayastha P, Davis D, Limoges J, O'Donnell C, Yue K (2009) Development of leadership self-efficacy and collective efficacy: adolescent girls across castes as peer educators in Nepal. Glob Public Health 4(3):284-302

Ramse (1992) An analysis of experiences secondary vocational and technical education and training in Nepal. Unpublished, Kathmandu

Scheyvens R (2000) Promoting women's empowerment through involvement in ecotourism: experiences from the third world. J Sustain Tour 8(3):232-249. https://doi.org/10.1080/09669580008667360

Sharma TN (1987) Role of Karnali Technical School. Jumla, Nepal in the preparation of youth for employment: a follow-up study of graduates and their employers. Unpublished Master's Thesis, Southern Illinois University at Carbondale

Shrestha P (2011) Primary teachers' perception and practice of continuing professional development. Master of Philosophy in Education, Kathmandu University, Dhulikhel, Nepal

Turner VW (2017) Liminality and communitas. Routledge, London, pp 169-187

UNESCO (2000) The Dakar framework for action. UNESCO, Dakar

Upadhyay R, Pradhan H, Grandon P (2011) Women in Nepalese tourism: opportunities and challenges. Pilgrims Pub., Varanasi

Verheul I, Thurik R (2001) Start-up capital: "does gender matter?" Small Bus Econ 16(4):329-346. https://doi.org/10.1023/a: 1011178629240

Wardle KM (2014) An assessment of work integrated learning (WIL) in hospitality tertiary education. Doctoral dissertation, University of Western Sydney, Australia

Wilkinson PF, Pratiwi W (1995) Gender and tourism in an Indonesian village. Ann Tour Res 22(2):283-299. https://doi.org/ 10.1016/0160-7383(94)00077-8

\section{Publisher's Note}

Springer Nature remains neutral with regard to jurisdictional claims in published maps and institutional affiliations. 